\title{
Sensitivity analysis of seepage field in groundwater reservoir based on orthogonal test method
}

\author{
Jiahuan $\mathrm{HE}^{1 *}$, Dong $L E I^{1}$, Yue $Z H A N G^{2}$, Xin $G A O^{1}$, Xiaoyu $W_{A N G}{ }^{1}$ \\ 1. Northwest Electric Power Test and Research Institute, China Datang Corporation Science and Technology Research Institute Co., Ltd, \\ 710016, Xi an, Shaanxi, China. \\ 2. Xianyang Research Institute of Water Conservancy and Hydropower Planning and Design, 712000, Xianyang, Shaanxi, China
}

\begin{abstract}
Based on the ADINA-T finite element software, the effects of different underground dam depths, widths and permeability coefficients on the seepage field in the underground reservoir were studied. Based on the sensitivity analysis and calculation of the three parameters of the underground dam based on the orthogonal experiment method, the depth and permeability coefficient of the underground dam have a significant effect on the sensitivity of the groundwater level drop height in front of the dam, the width and the permeability coefficient have a significant effect on the maximum flow velocity, and depth has great influence on seepage flow.
\end{abstract}

\section{Introduction}

The groundwater reservoir is a kind of water conservancy project that uses porous loose media as a water storage medium. It has the advantages of low construction cost, low risk, and small negative effect on the operating environment. Having reached saturation, the groundwater reservoir can be used as a new special reservoir to realize the conversion and utilization of surface water and groundwater[1]. In underground water reservoirs, underground dams are built to prevent the flow of underground water, store underground water, cut off the passage of groundwater out of the reservoir, form a relatively closed storage space for underground water reservoirs, and change the flow of groundwater. In general, the dam body material should meet sufficient durability and low permeability, be able to withstand a certain penetration water pressure, and be able to form an effective storage capacity as large as possible, so there must be sufficient depth and width for the underground dam[2].

Studying the sensitivity effect of underground dam parameters on groundwater reservoir seepage flow can reduce the parameter calibration workload and provide reference for design. The traditional parameter sensitivity adopts the single factor analysis method. Due to the mutual influence and common change of the actual parameters, the result analysis does not agree with the actual situation[3]. The orthogonal test method is widely used in the sensitivity analysis of the model parameters of water conservancy projects[4]. In this paper, the depth, width and permeability coefficient of different underground dams are discussed. Based on the finite element software ADINA-T module, the analysis and analysis of the influence law and sensitivity characteristics of underground dam parameters on the seepage field of underground water reservoirs are provided, which provide reliable seepage for design analysis Basis of load calculation.

\section{Mathematical model of finite element for seepage calculation}

\subsection{Seepage calculation finite element model}

From the continuity of water flow, the basic differential equation for the calculation of stable seepage can be expressed as [5]:

$$
\frac{\partial}{\partial x}\left(k_{x} \frac{\partial H}{\partial x}\right)+\frac{\partial}{\partial y}\left(k_{y} \frac{\partial H}{\partial y}\right)+\frac{\partial}{\partial z}\left(k_{z} \frac{\partial H}{\partial z}\right)=0
$$

The boundary conditions can be divided into:

Given the water head on the boundary $S_{l}$, there are:

$$
\left.H(x, y, z)\right|_{S_{1}}=\varphi(x, y, z) \quad(x, y, z) \in S_{1}
$$

Where: $\varphi$ is the water head potential function;

Given the normal velocity on the boundary $S_{2}$, there is:

$$
k \frac{\partial H}{\partial n}=q(x, y, z) \quad(x, y, z) \in S_{2}
$$

Where: $n$ is the direction of the outer normal of the boundary $S_{2}$, and $\mathrm{q}$ is the flow rate;

2.2 Design principle of orthogonal test method

* Corresponding author: 1024104175@qq.com 
The orthogonal test method is based on orthogonal science, and the test is arranged with reference to the orthogonal table, which has balanced dispersion and neat comparability. The orthogonal table is represented by $L_{n}\left(t^{c}\right)$, where: $\mathrm{L}$ is the code of the orthogonal table; $\mathrm{n}$ is the total number of tests; $t$ is the number of factors; $c$ is the number of orthogonal columns. The orthogonal test table reflects the balance of the number of experiments at the same level and the uniformity of the distribution of test points. In this paper, the $L_{16}\left(4^{4}\right)$ orthogonal table is used as shown in Table 1.

Table 1. $L_{16}\left(4^{4}\right)$ orthogonal test table

\begin{tabular}{|c|c|c|c|c|}
\hline \multirow{2}{*}{ Test number } & \multicolumn{4}{|c|}{ Column number } \\
\cline { 2 - 5 } & 1 & 2 & 3 & 4 \\
\hline 1 & 1 & 1 & 1 & 1 \\
\hline 2 & 1 & 2 & 2 & 2 \\
\hline 3 & 1 & 3 & 3 & 3 \\
\hline 4 & 1 & 4 & 4 & 4 \\
\hline 5 & 2 & 1 & 2 & 3 \\
\hline 6 & 2 & 2 & 1 & 4 \\
\hline 7 & 2 & 3 & 4 & 1 \\
\hline 8 & 2 & 4 & 3 & 2 \\
\hline 9 & 3 & 4 & 3 & 4 \\
\hline 10 & 3 & 2 & 4 & 3 \\
\hline 11 & 3 & 3 & 1 & 2 \\
\hline 12 & 3 & 4 & 2 & 1 \\
\hline 13 & 4 & 1 & 4 & 2 \\
\hline 14 & 4 & 2 & 3 & 1 \\
\hline 15 & 4 & 3 & 2 & 4 \\
\hline 16 & 4 & 4 & 1 & 3 \\
\hline
\end{tabular}

The results analysis method of the orthogonal test method is usually divided into two kinds of range analysis method and variance analysis method. In this paper, the sensitivity analysis of the orthogonal test results is carried out by the range analysis method.

The calculation of statistical parameters by range analysis method can be shown in formula (4):

$$
K_{i j}=\frac{1}{n} \sum_{k=1}^{n} Y_{k}-\bar{Y}
$$

Where:

$K_{i j} \longrightarrow$ The average value of the test results of the $j$ factor at the $i$ level

$$
\begin{aligned}
& \mathrm{n}-\text { Number of trials with factor } \mathrm{j} \text { at level } \mathrm{i} \\
& \bar{Y} \quad \text { Test index value } \\
& \quad \text { average value }
\end{aligned}
$$

\section{Calculation model and boundary conditions}

In the study of underground dam models with different parameters of the underground water reservoir, this paper selects a part of the storage space of an underground water reservoir as a calculation example, and calculates the corresponding seepage field by studying different underground dam parameters. The seepage field of the groundwater reservoir is analyzed by combining the groundwater level, seepage velocity and seepage flow. Through consulting data and related soil mechanics tests, the simulation setting parameters of each layer can be obtained as shown in Table 2.

Table 2. Model calculation parameter table

\begin{tabular}{|c|c|c|c|}
\hline Aquifer medium & $\begin{array}{c}\text { Weight( } \\
\left.\mathrm{kN} \cdot \mathrm{m}^{-3}\right)\end{array}$ & $\begin{array}{c}\text { Permeability } \\
\text { coefficient }\left(\mathrm{m} \cdot \mathrm{s}^{-1}\right)\end{array}$ & $\begin{array}{c}\text { propert } \\
\mathrm{y}\end{array}$ \\
\hline Loose medium & 17 & $1.4 \times 10^{-4}$ & $\begin{array}{c}\text { isotropi } \\
\mathrm{c}\end{array}$ \\
\hline $\begin{array}{c}\text { Concrete } \\
\text { underground dam }\end{array}$ & 23.5 & $1 \times 10^{-8}$ & $\begin{array}{c}\text { isotropi } \\
\mathrm{c}\end{array}$ \\
\hline Bedrock & - & $1 \times 10^{-8}$ & $\begin{array}{c}\text { isotropi } \\
\mathrm{c}\end{array}$ \\
\hline
\end{tabular}

The calculation model uses the ADINA-T module, the model range is $100 \mathrm{~m} \times 200 \mathrm{~m} \times 70 \mathrm{~m}$, and the local grid is encrypted at the underground dam, using a four-node rectangular grid, the grid density is $0.25 \mathrm{~m}$, the remaining part is divided by quadrilateral elements, the maximum grid density is $2 \mathrm{~m}$, and a total of 123363 nodes and 113380 elements are divided, as shown in Figure 1. In this model, it is assumed that the initial groundwater level is at the ground surface, with a fixed head boundary of $90 \mathrm{~m}$ on the upstream side and a fixed head boundary of $70 \mathrm{~m}$ on the downstream side, and the remaining boundaries are impervious boundaries.

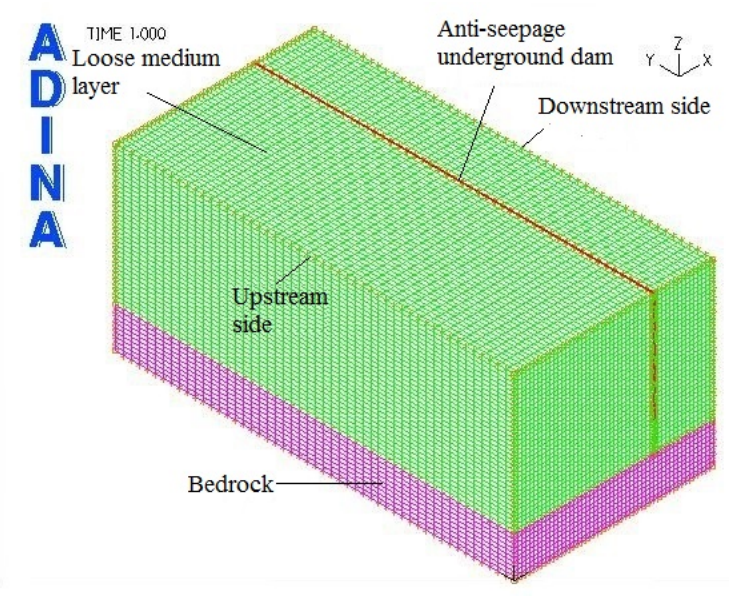

Figure 1. Meshing model (unit: $\mathrm{m}$ )

\section{Parameter sensitivity analysis of underground dam based on orthogonal test method}

By studying the influence of different underground dam parameters on groundwater level, four test levels of each parameter were selected, and the experimental factors and levels of sensitivity analysis for orthogonal test method were selected., The three main parameters of permeability coefficient $k$ are used for sensitivity analysis. Each parameter is set with 4 test levels. The values of the test factors in the sensitivity analysis are shown in Table 3 . The results were analyzed using range analysis method for sensitivity analysis. 
Table 3. Factor levels in orthogonal experiments

\begin{tabular}{|c|c|c|c|}
\hline Factor level & $d / \mathrm{m}$ & $w / \mathrm{m}$ & $\mathrm{k} /\left(\mathrm{m} \cdot \mathrm{s}^{-1}\right)$ \\
\hline 1 & 55 & 0.25 & $1 \times 10^{-6}$ \\
\hline 2 & 45 & 0.5 & $1 \times 10^{-7}$ \\
\hline 3 & 35 & 0.75 & $1 \times 10^{-8}$ \\
\hline 4 & 25 & 1 & $1 \times 10^{-9}$ \\
\hline
\end{tabular}

Bring the various parameters in the table into the $\mathrm{L}_{16}$ $\left(4^{4}\right)$ orthogonal test table, set the first column of empty columns, compose the corresponding test plan and calculate it in the numerical model. The height $\Delta h$, the maximum flow velocity $v_{\max }$, and the single-wide flow $q$ are used as calculation indexes, and filled in Table 4, and the sensitivity of each parameter of the underground dam to the test index is solved according to the range analysis method.

Table 4. Design scheme and calculation result of orthogonal experiment

\begin{tabular}{|c|c|c|c|c|c|c|}
\hline & $\begin{array}{c}d / \\
\mathrm{m}\end{array}$ & $w / \mathrm{m}$ & $\begin{array}{c}k / \\
\left(\mathrm{m} \cdot \mathrm{s}^{-1}\right. \\
)\end{array}$ & $\Delta h / \mathrm{m}$ & $\begin{array}{c}v_{\max } / \\
\left(10^{-4} \mathrm{~m} \cdot \mathrm{s}^{-}\right. \\
1)\end{array}$ & $\begin{array}{c}q / \\
\left(10^{-4} \mathrm{~m}^{3} \cdot \mathrm{s}^{-}\right. \\
\left.1 \cdot \mathrm{m}^{-1}\right)\end{array}$ \\
\hline 1 & 55 & 0.25 & $1 \times 10^{-6}$ & 10.281 & 1.430 & 6.2337 \\
\hline 2 & 45 & 0.5 & $1 \times 10^{-7}$ & 6.237 & 1.970 & 11.833 \\
\hline 3 & 35 & 0.75 & $1 \times 10^{-8}$ & 7.120 & 1.797 & 14.476 \\
\hline 4 & 25 & 1 & $1 \times 10^{-9}$ & 8.861 & 1.235 & 3.7411 \\
\hline 5 & 55 & 0.5 & $1 \times 10^{-8}$ & 4.224 & 2.235 & 9.4378 \\
\hline 6 & 45 & 0.25 & $1 \times 10^{-9}$ & 5.594 & 3.202 & 12.164 \\
\hline 7 & 35 & 1 & $1 \times 10^{-6}$ & 8.824 & 1.137 & 13.343 \\
\hline 8 & 25 & 0.75 & $1 \times 10^{-7}$ & 9.064 & 1.533 & 16.271 \\
\hline 9 & 55 & 0.75 & $1 \times 10^{-9}$ & 4.109 & 2.117 & 9.4452 \\
\hline 10 & 45 & 1 & $1 \times 10^{-8}$ & 5.529 & 1.526 & 11.757 \\
\hline 11 & 35 & 0.25 & $1 \times 10^{-7}$ & 7.971 & 2.172 & 14.011 \\
\hline 12 & 25 & 0.5 & $1 \times 10^{-6}$ & 10.514 & 1.240 & 15.139 \\
\hline 13 & 55 & 1 & $1 \times 10^{-7}$ & 4.557 & 1.934 & 9.2138 \\
\hline 14 & 45 & 0.75 & $1 \times 10^{-6}$ & 8.509 & 1.473 & 10.515 \\
\hline 15 & 35 & 0.5 & $1 \times 10^{-9}$ & 7.119 & 1.910 & 14.512 \\
\hline 16 & 25 & 0.25 & $1 \times 10^{-8}$ & 9.008 & 1.636 & 16.111 \\
\hline
\end{tabular}

The results of the range analysis method for the test indexes $\Delta h, v_{\max }$ and $q$ are shown in Table 5, Table 6 and Table 7.

Table 5. Range analysis of $\Delta h$

\begin{tabular}{|c|c|c|c|}
\hline Factor & $d / \mathrm{m}$ & $w / \mathrm{m}$ & $k /\left(\mathrm{m} \cdot \mathrm{s}^{-1}\right)$ \\
\hline$K_{I}$ & -1.552 & 0.868 & 2.187 \\
\hline$K_{2}$ & -0.878 & -0.322 & -0.388 \\
\hline$K_{3}$ & 0.414 & -0.145 & -0.875 \\
\hline$K_{4}$ & 2.017 & -0.402 & -0.924 \\
\hline$R_{j}$ & 3.569 & 1.271 & 3.111 \\
\hline \multicolumn{4}{|c|}{ Sensitivity: $d>k>w$} \\
\hline
\end{tabular}

Table 6. Range analysis of $v_{\max }$

\begin{tabular}{|c|c|c|c|}
\hline Factor & $d / \mathrm{m}$ & $w / \mathrm{m}$ & $\mathrm{k} /\left(\mathrm{m} \cdot \mathrm{s}^{-1}\right)$ \\
\hline$K_{1}$ & 0.145 & 0.326 & -0.464 \\
\hline$K_{2}$ & 0.259 & 0.055 & 0.118 \\
\hline$K_{3}$ & -0.030 & -0.054 & 0.014 \\
\hline$K_{4}$ & -0.373 & -0.326 & 0.332 \\
\hline$R_{j}$ & 0.632 & 0.652 & 0.796 \\
\hline \multicolumn{4}{|c|}{ Sensitivity: $k>w>d$} \\
\hline
\end{tabular}

Table 7. Range analysis of $q$

\begin{tabular}{|c|c|c|c|}
\hline Factor & $d / \mathrm{m}$ & $w / \mathrm{m}$ & $k /\left(\mathrm{m} \cdot \mathrm{s}^{-1}\right)$ \\
\hline$K_{1}$ & -3.180 & 0.367 & -0.455 \\
\hline$K_{2}$ & -0.195 & 0.968 & 1.069 \\
\hline$K_{3}$ & 2.323 & 0.914 & 1.183 \\
\hline$K_{4}$ & 1.053 & -2.249 & -1.797 \\
\hline$R_{j}$ & 5.503 & 3.217 & 2.980 \\
\hline \multicolumn{4}{|c|}{ Sensitivity: $d>w>k$} \\
\hline
\end{tabular}

In the results of the range analysis method for the maximum flow rate $\Delta h$ of the test index, the sensitivity of each factor to it is: $d>k>w$. In the results of the range analysis of the maximum flow velocity $v_{\max }$ of the test index, the sensitivity of each factor to it is: $k>w>d$. For the test index single-width flow $q$ under the range analysis method, the sensitivity of each factor to it is: $d>w>k$. After performing range analysis on each test index $d, w$, and $k$, the obtained range histogram is shown in Figure 2.

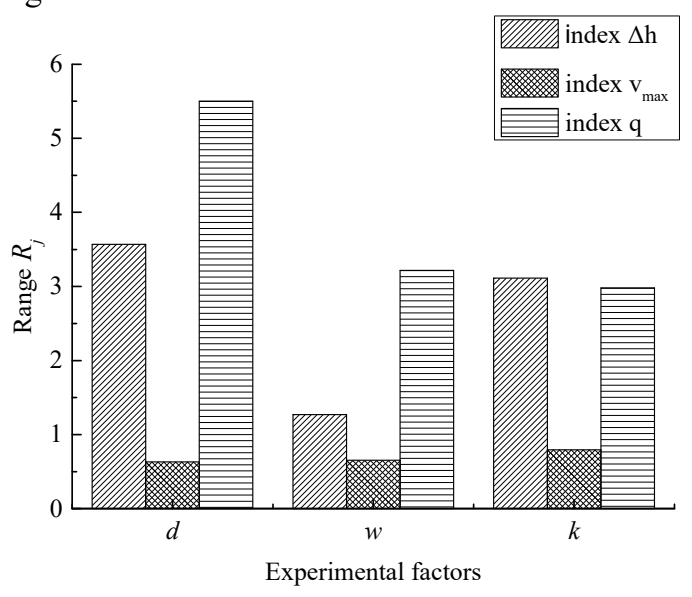

Figure 2. Comparison results of sensitivity analysis of each test index parameter

It can be seen from Figure 8 that in the numerical calculation model, the depth $d$ and the permeability coefficient $k$ have the most significant influence on the drop height of the groundwater level before the dam. Among them, the sensitivity of $d$ is the largest and the sensitivity of $w$ is the smallest; Similarity, $k$ has the greatest influence; $d$ has a greater influence on the single-width flow of seepage, followed by $\mathrm{w}$ and $k$, and the two have the same sensitivity.

\section{Conclusion}

By comparing and analyzing the changes of the seepage field of the groundwater reservoir under the depth $d$, 
width $w$ and permeability coefficient $k$ of different underground dams, the following conclusions can be obtained:

(1)When the depth of the underground dam increases, the water level in front of the dam will continue to rise, and the height of the groundwater level before the dam will have a quadratic function relationship with the depth. The width of the underground dam has no significant effect on the drop of the groundwater level. The permeability coefficient of the underground dam will affect the drop height of the water level before the underground dam. When the permeability coefficient value reaches $1 \times 10^{-8} \mathrm{~m} / \mathrm{s}$, the effect of the water level before the underground dam will no longer be obvious.

(2)According to the sensitivity analysis of underground dam parameters based on orthogonal experiment method, $d$ and $k$ have a significant effect on the sensitivity of the groundwater level drop height in front of the dam; $k$ and $w$ have a significant effect on the maximum flow velocity; $d$ has a single width of seepage flow has a greater impact.

\section{References}

1. BH Liu, WP Wang, GF Lv. The Effects of Water Recharge on Wanghe Groundwater Reservoir[J]. International Conference on Challenges in Environment, 2010, 2: 247-249.

2. Zhang G, Feng G, Li X, et al. Flood effect on groundwater recharge on a typical silt loam soil[J]. Water, 2017, 9, 523

3. Scanlon BR, Keese KE, Flint AL, et al. Global synthesis of groundwater recharge in semiarid and arid regions[J]. Hydrological Processes, 2010, 20(15): 3335-3370.

4. Shi XQ, Jiang SM, Xu HX, et al. The effects of artificial recharge of groundwater on controlling land subsidence and its influence on groundwater quality and aquifer energy storage in Shanghai, China[J]. Environmental Earth Sciences, 2016, 75(3): 195.

5. ADINA theory and modeling guide volume II: ADINA-T[M]. ADINA R\&D. 2003 